\title{
ARBORIZAÇÃO DE VIAS PÚBLICAS E A UTILIZAÇÃO DE ESPÉCIES EXÓTICAS: O CASO DO BAIRRO CENTRO DE PATO BRANCO/PR
}

\author{
TREE PLANTING ON PUBLIC ROADS AND THE UTILIZATION OF EXOTIC \\ SPECIES: THE DOWNTOWN CASE IN PATO BRANCO/PR
}

\author{
Lenir Maristela SILVA ${ }^{1}$ \\ lonete $\mathrm{HASSE}^{2}$ \\ Renata MOCCELIN ${ }^{3}$ \\ Adriane Rodrigues ZBORALSKI ${ }^{4}$
}

\begin{abstract}
RESUMO
O objetivo deste trabalho foi identificar as espécies arbóreas que compõem a arborização viária do bairro Centro de Pato Branco (PR). As árvores foram identificadas individualmente pelo nome científico da espécie, nome vulgar, nome da rua e do logradouro mais próximo. Para a identificação das espécies foram coletadas amostras férteis que foram herborizadas. Além disso, cada espécie foi fotografada. Os dados foram coletados nos meses de maio a novembro de 2005 , sendo percorridos $31,5 \mathrm{~km}$ em trinta e quatro ruas. Foram identificados 3191 espécimes arbóreos, compreendendo 47 espécies diferentes. Aárea inventariada apresenta predominância da espécie Ligustrum lucidum W. T. Aiton (62,4\%), a qual não é nativa da região e está na lista das plantas invasoras no Brasil. Na seqüência aparecem Lagerstroemia indica L. (11,4\%), Schinus molle L. (6,3\%), Bauhinia variegata L. (3,8\%), e outras (16,1\%). Das espécies mais abundantes apenas uma é nativa do Brasil (Schinus molle). Enquadradas como "outras" encontram-se 43 espécies, porém, com freqüência individual menor que 2,95\%. Dessas espécies, vinte e duas são nativas do Brasil, e vinte e cinco são exóticas. Esse resultado demonstra que no bairro Centro de Pato Branco há o predomínio de uma espécie, e mais de $60 \%$ dos espécimes são exóticos.
\end{abstract}

Palavras-chave: arborização urbana; espécies alienígenas invasoras; Ligustrum lucidum.

\begin{abstract}
This objective in this work went identify the arboreal species that compound the tree planting in the downtown area of Pato Branco-PR and a critical discussion about the utilization of exotic species. The trees with were identified individually by the use of a spread sheet to write down the cientific name of the specie, common name, name of the street and the name of the closest common grounds. For the identification of the species they were collected fertile samples that were herborized. Besides, each species was photographed. The data were collected from May to November of 2005 . Hey were traveled $31,5 \mathrm{~km}$ in thirty four streets. Were identified 3191 arboreal specimens, understanding 47 different species The inventoried area presents the predominance of the specie Ligustrum lucidum W. T. Aiton (62,4\%). This specie is not native and it is on the list of invader plants. In the sequence appear Lagerstroemia indica L. $(11,4 \%)$, Schinus molle L. $(6,3 \%)$, Bauhinia variegata L. $(3,8 \%)$, and others $(16,1 \%)$. From the most abundant species only one is from Brazil (Schinus molle). Framed ad "others" are found varied species but with a very individual frequence lower to $2,95 \%$. From these species, twenty-two are native and twenty-five are exotic. The result demonstrates that the downtown area doesn't have a peculiar local bioma identity, because, besides there being prevalence of species, more than $60 \%$ of the specimens is exotic.
\end{abstract}

Key-words: urban tree planting; alien invaders species; Ligustrum lucidum.

\footnotetext{
${ }^{1}$ Bióloga, Mestre em Botânica/UFPR, Doutora em Produção Vegetal/UFPR. Professora Adjunta da UTFPR. Via do Conhecimento, Km 01, 85.503-390 - Pato Branco/PR. lenir@utfpr.edu.br;

${ }^{2}$ Bióloga, Mestre em Ciência do solo/UFPR, Doutora em Produção Vegetal/UFPR. Professora Adjunta da UTFPR;

${ }^{3}$ Acadêmica de Iniciação Científica do Curso de Agronomia da UTFPR;

${ }^{4}$ Acadêmica do Curso de Agronomia da UTFPR.
} 


\section{INTRODUÇÃO}

O movimento ambientalista nas três últimas décadas fez com que os habitantes das cidades no mundo ocidental desenvolvessem uma postura bem distinta do que prevalecia até 100 anos atrás para com a natureza e as plantas. Boa parte da população urbana valoriza as plantas e reconhece o benefício que as áreas verdes representam para o ser humano (SALATINO, 2001).

Se por um lado, é inegável o valor acrescentado à qualidade de vida quando se arboriza uma cidade, levando-se em conta fatores como a ornamentação, a melhoria microclimática e a diminuição da poluição, por outro lado, a inserção desses vegetais ao meio urbano não é tão simples, já que não é o habitat mais apropriado ao seu desenvolvimento. A instituição de padrões como espécies de porte alto, médio e baixo, muito comum em manuais e guias de arborização são insuficientes quando o trabalho envolve variáveis tão diferentes da malha urbana juntamente com as peculiaridades ecológicas de cada espécie. Por exemplo, o porte alto e copa mais fechada, de algumas árvores utilizadas na arborização urbana, mesmo em passeios largos e sem fiação aérea, podem reduzir em até $11 \%$ o nível de iluminação pública de ruas, caso o sistema de iluminação seja tradicional (SARTORI NETO, 1988). Um outro exemplo, refere-se a espécie Bauhinia variegata que apesar de apresentar pequeno porte não é recomendada para calçadas porque apresenta esgalhamento volumoso da copa e uma fragilidade à queda de galhos (BIONDI e ALTHAUS, 2005).

Além do diferencial da extensão territorial de cada cidade, um quesito fundamental para arborização urbana é a consideração das características climáticas e pedológicas específicas de cada local, não podendo dessa maneira simplesmente importar soluções de outros locais e, principalmente, de regiões fitogeográficas distintas.

Dentre as soluções mais freqüentes está a utilização de plantas exóticas (alienígenas). A introdução de espécies é a segunda maior ameaça mundial à biodiversidade, perdendo apenas para a destruição de habitat's por ações antrópicas diretas (ZILLER, 2001).

As espécies que não são nativas, além de não se comportarem do mesmo modo que no ambiente de origem, podem causar diversos danos ao ambiente, como a perda da biodiversidade, modificações dos ciclos e características naturais dos ecossistemas atingidos e a alteração fisionômica da paisagem natural, além de conseqüências econômicas vultosas (ZILLER, 2001).

Não houve nenhum estudo acadêmico que apurasse a realidade da arborização urbana no bairro Centro de Pato Branco, e que pudesse subsidiar uma argumentação à melhoria da paisagem urbana, conseqüentemente, da qualidade vida. Considerando que para qualquer planejamento da arborização urbana não se pode prescindir de um inventário criterioso, o presente trabalho teve por objetivo identificar essa composição através de um censo total das espécies arbóreas presentes nesse bairro. Com isso, pretende-se ampliar a argumentação da importância da vegetação no meio urbano e da conservação da biodiversidade nativa junto à comunidade acadêmica e a população local.

\section{MATERIAL E MÉTODOS}

A área inventariada localiza-se em Pato Branco, Paraná, no bairro Centro (Figura 1). Este município localiza-se na região sudoeste do Paraná, no terceiro planalto paranaense. Apresenta a ocorrência de Cfa - clima subtropical úmido mesotérmico (IAPAR, 2000), destacando-se o solo do tipo Latossolo Vermelho Distroférrico (EMBRAPA, 1999). Pato Branco encontra-se a $760 \mathrm{~m}$ de altitude, com latitude de $26^{\circ} 13^{\prime} 46^{\prime \prime}$ S e longitude de $52^{\circ} 40^{\prime}$ 14" W-GR. A população total corresponde a 62.167 habitantes, sendo que destes 56.739 , correspondem a população urbana e 8.190 correspondem aos habitantes do bairro Centro (IBGE, 2000). A área urbana apresenta $71,23 \mathrm{~km}^{2}$. Foram percorridos 31,5 $\mathrm{km}$ em trinta e quatro ruas que compõem o bairro Centro. O bairro Centro de Pato Branco caracterizase como residencial e comercial. Esse bairro não possui cadastro histórico da sua arborização.

A vegetação da região na qual se localiza a área urbana do município era originariamente coberta por Floresta Ombrófila Mista Montana. Esta formação ocupa as regiões planálticas do Paraná, apresentando faixa de ocorrência altitudinal entre 400 e 1.000 metros. O dossel contínuo varia em torno de 20 metros de altura, mas as araucárias atingem até 25 metros. A Floresta Ombrófila Mista também é conhecida por "Floresta de Pinheiros", "Pinheirais", "Zona dos Pinhais", "Matas de Araucária" e "Florestas com Araucária" (IBGE, 1992).

Para localização das vias públicas, bem como a obtenção de sua extensão, foi utilizada uma planta planialtimétrica na escala 1:10.000, elaborada pelo IPPUPB (Instituto de Pesquisa e Planejamento Urbano de Pato Branco).

Considerando a importância sócioeconômica do bairro para a cidade, optou-se pelo levantamento total das espécies arbóreas em todas as ruas. As árvores foram identificadas individualmente na área inventariada utilizando-se uma planilha para anotação do nome científico da espécie, nome vulgar, nome da rua e do logradouro mais próximo. Os dados foram coletados no período de maio a novembro de 2005. 


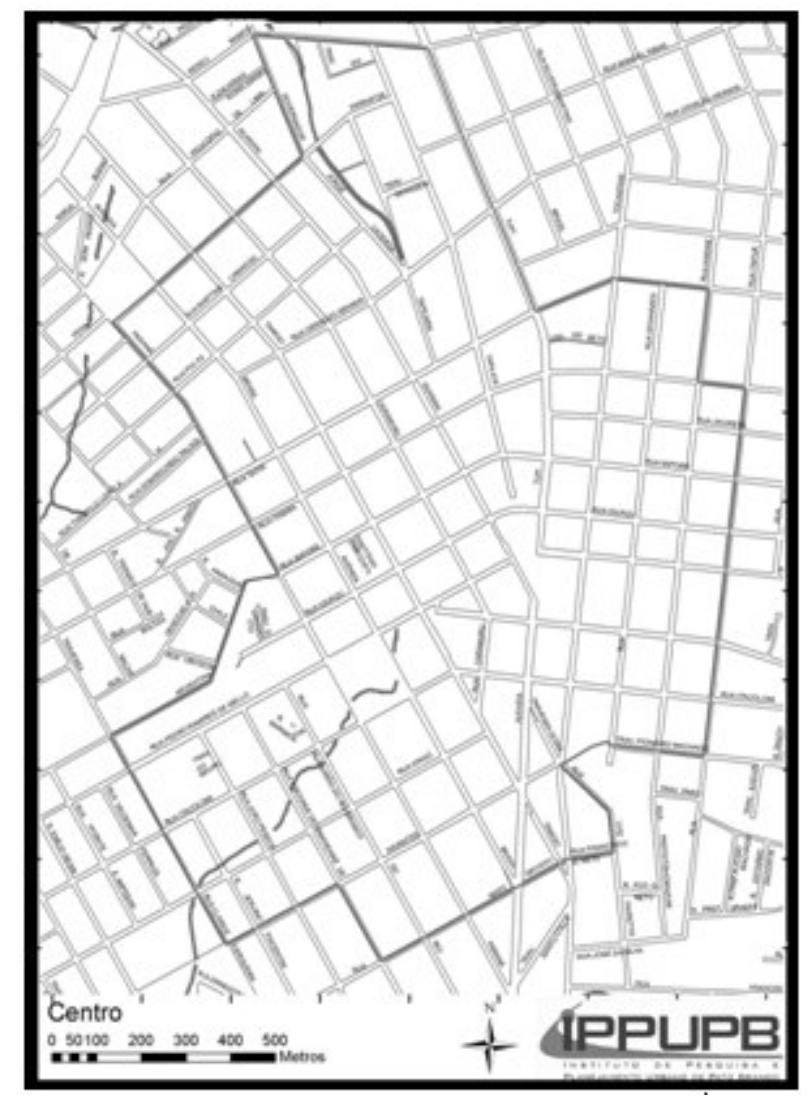

FIGURA 1 - Bairro Centro de Pato Branco/PR/2005 delimitado pela linha contínua.

Para a identificação das espécies foram coletadas amostras férteis que foram herborizadas. Além disso, cada espécie foi fotografada.

A freqüência (\%) de cada espécie foi calculada através da razão entre o número de indivíduos da espécie e o número total de indivíduos do bairro.

\section{RESULTADOS E DISCUSSÃO}

No bairro Centro de Pato Branco foram identificados 3191 espécimes arbóreos, compreendendo 47 espécies diferentes, com a predominância de quatro espécies (Tabela 1). A espécie mais abundante, Ligustrum lucidum W. T. Aiton (alfeneiro, ligustro) é a espécie mais comum nas cidades Sul-Brasileiras e por isso é chamada vulgarmente de "árvore-de-prefeito" (BACKES e IRGANG, 2004). Essa espécie não é nativa do Brasil e está na lista das plantas exóticas consideradas invasoras, pois a sua dispersão e seu crescimento ocorrem de maneira rápida fazendoa competir e impedir a regeneração de plantas nativas. No Paraná ela é invasora da Floresta Ombrófila Mista (INSTITUTO HÓRUS, 2005). Em 15 amostras aleatórias na cidade de Curitiba (PR), Milano (1985) identificou noventa e três espécies arbóreas num censo total de 4.382 espécimes. Dessas $24 \%$ foram da espécie Lagerstroemia indica e $14,7 \%$ foram de Ligustrum lucidum. Ou seja, duas espécies exóticas somaram quase $40 \%$ da composição arbórea. Em outro estudo realizado na região central de Horizontina (RS), de um total de 3.160 árvores inventariadas, Floriano et al. (2004) identificou o Ligustrum japonicum (746) em maior abundância. Nesse estudo também prevaleceram espécies exóticas. No bairro Centro de Nova Iguaçu (RJ), também foi identificada uma maior freqüência de espécimes de espécies exóticas (ROCHA et al., 2004).

O gênero Ligustrum também é invasor em outros países da América do Sul (GISP, 2005; OJASTI et al., 2001). Muitas espécies deste gênero são apontadas como invasoras em diversos países, como - Ligustrum lucidum que é indicado como espécie invasora nos Estados Unidos da América, Hawai e Nova Zelândia (STARR et al., 2003).

Os frutos do ligustro são tóxicos para os serem humanos, causando náusea, dores de cabeça, dores abdominais, vômitos, diarréia, pressão baixa e hipotermia (INSTITUTO HÓRUS, 2005), bem como o pólen das flores pode causar alergia (BACKES e IRGANG, 2004; BIONDI e ALTHAUS, 2005). Em Curitiba-PR, desde 1999, não há mais produção de mudas dessa espécie no horto municipal devido ao seu potencial invasor (BIONDI e ALTHAUS, 2005). A espécie L. lucidum não é recomendada para a arborização urbana devido ao cultivo excessivo e ao potencial dispersor (BACKES e IRGANG, 2004). 
SILVA, L.M. et al. Arborização de vias públicas...

TABELA 1 - Freqüência das espécies arbóreas no bairro Centro de Pato Branco (PR) em 2005.

\begin{tabular}{lccc}
\hline Espécie & Número de espécimes & Freqüência (\%) & Origem $^{1}$ \\
\hline Ligustrum lucidum W.T. Aiton & 1992 & 62,4 & China e Coréia \\
Lagerstroemia indica L. & 363 & 11,4 & Ásia, Oceania \\
Schinus molle L. & 200 & 6,3 & Brasil e \\
& & & América do Sul \\
Bauhinia variegata L. & 121 & 3,8 & Ásia \\
Outras & 515 & 16,1 & - \\
\hline TOTAL & 3191 & 100 & \\
\hline
\end{tabular}

${ }^{1} \mathrm{~A}$ origem das espécies foi obtida por meio das seguintes fontes: BACKES e IRGANG (2002); BACKES e IRGANG (2004).

A espécie que aparece em segundo lugar em freqüência (Tabela 1) no bairro Centro de Pato Branco é a Lagerstroemia indica L., que também é exótica, e por ser de pequeno porte é freqüentemente recomendada (CEMIG, 2001; COPEL, 2005; SANTOS e TEIXEIRA, 2001) para arborização urbana. Essa espécie pode ser atacada por míldio, mancha foliar, mancha negra e podridão da raiz (BIONDI e ALTHAUS, 2005).

A espécie Schinus molle L., em terceira colocação em termos de freqüência (Tabela 1), é a única espécie nativa do bioma local (ISERNHAGEN et al., 2002) no rol das árvores mais abundantes na região inventariada. Essa espécie apresenta a ramificação muito pendente. Devido ao pequeno porte é muito comum nas cidades do sul do Brasil (BACKES e IRGANG, 2004).

Bauhinia variegata $L$. que aparece em quarto lugar em freqüência na área estudada (Tabela 1), também é uma espécie exótica, largamente empregada na arborização. Essa é uma espécie que necessita de podas freqüentes por apresentar esgalhamento volumoso e baixo da copa (BIONDI e ALTHAUS, 2005).

Cerca de $16,1 \%$ dos espécimes presentes no Centro da cidade de Pato Branco foram enquadradas na categoria "outras" por ser um número de 43 espécies, contudo com baixa freqüência individual. A lista dessas espécies pode ser observada na Tabela 2.

Dessas espécies, vinte e uma são brasileiras e vinte e duas são exóticas. Somando-se esse resultado às espécies da Tabela 1 , tem-se um total de vinte e cinco exóticas e vinte e duas nativas na área estudada. Todavia, a freqüência de espécimes de árvores exóticas é muito mais alta, ou seja, superior a $60 \%$ dos indivíduos arbóreos. Segundo Rangel (2005), cerca de $80 \%$ das ruas das cidades brasileiras são arborizadas com espécies exóticas (RANGEL, 2005).

Das espécies listadas na Tabela 2, Cupressus lusitanica, Cupressus macrocarpa e Grevillea robusta não podem receber nenhum tipo de poda, pois apresentam arquitetura monopodial (SANTOS e TEIXEIRA, 2001). Já espécies como Enterolobium contortisiliquum, Eriobotrya japonica, Hovenia dulcis, Mangifera indica, Melia azedarach, Parapiptadenia rigida, Persea americana, Ficus enormis, Ficus lyrata e Tipuana tipu, são espécies de grande porte, portanto não compatíveis com calçadas (SANTOS e TEIXEIRA, 2001). Outro aspecto polêmico na arborização é a presença de espécies frutíferas comestíveis para os humanos. O uso de espécies frutíferas depende de aspectos culturais e também da conscientização da população. No caso de querer utilizar frutíferas em calçadas deve-se optar pelo uso de espécies que apresentem frutos pequenos, leves e não carnosos (BIONDI e ALTHAUS, 2005). Contudo, a utilização de frutíferas nativas que possam servir de alimento para a avifauna, tem sido incentivada (RGE, 2000; COELBA, 2002) No presente censo, aparecem onze espécies frutíferas comestíveis para os humanos: Citrus sinensis, Eriobotrya japonica, Eugenia uniflora, Hovenia dulcis, Mangifera indica, Morus Alba, Persea americana, Plinia trunciflora, Psidium catleianum, Psidium guajava, Rollinia rugulosa. A Scheflera actinophylla, também não é indicada para calçadas, já que possui pouca folhagem, sendo mais apropriada para jardins e praças (BACKES e IRGANG, 2004).

Além do Ligustrum lucidum, destacam-se na Tabela 2 espécies que já se encontram na lista de espécies invasoras no Brasil, sendo elas: Acacia podalyriifolia, Eriobotrya japonica, Grevillea robusta, Hovenia dulcis, Mangifera indica, Melia azedarach, Morus alba, Pittosporum undulatum e Spathodea campanulata (INSTITUTO HÓRUS, 2006). Evidentemente, a invasão dessas espécies não ocorre do mesmo modo em todos os biomas brasileiros (ZILLER, 2001).

Das espécies supramencionadas, cabe destacar algumas considerações sobre a espécie africana Spathodea campanulata. É uma árvore de elevada beleza ornamental e, por isso, já há muitos anos é indicada para o paisagismo. Entretanto, além da intensa capacidade de regeneração natural, que impede a sucessão natural de florestas nativas, ela também oferece mais um perigo: suas flores apresentam alcalóides tóxicos que chegam a matar abelhas e beija-flores nativos (GISP, 2005; TRIGO e SANTOS, 2000).

O caso do bairro Centro de Pato Branco não é muito diferente de outras cidades brasileiras, nas quais há baixa diversidade de espécies arbóreas, o que pode favorecer gradativamente a dizimação de determinada população arbórea pela ocorrência de predadores (SILVA e BORTOLETO, 2005). 
SILVA, L.M. et al. Arborização de vias públicas...

TABELA 2 - Origem e freqüência de outras espécies arbóreas existentes no bairro Centro de Pato Branco (PR) em 2005.

\begin{tabular}{|c|c|c|c|}
\hline Espécie & Nome vulgar & Origem & Freqüência \% \\
\hline Acacia podalyriifolia Cunn. Ex. G. Don. & Acácia mimosa & Austrália & 0,11 \\
\hline "Bauhinia forficata Link. & Pata-de-vaca & \begin{tabular}{|lr} 
Brasil, & Argentina, \\
Paraguai, & Uruguai, \\
Bolívia & \\
\end{tabular} & 0,05 \\
\hline${ }^{*}$ Bougainvillea glabra Choisy & Primavera & Brasil & 0,05 \\
\hline Caesalpinia peltophoroides Benth. & Sibipiruna & Brasil & 0,11 \\
\hline Callistemon speciosus (Bonpl.) Sweet. & Escova-de-garrafa & Austrália & 0,22 \\
\hline Cinnamomum zeylanicum (Breyn.) BI. & Cinamomo & Ceilão & 0,71 \\
\hline Citrus sinensis L. Osb. & Laranja & Ásia & 0,93 \\
\hline Cupressus lusitanica Mill. & Cipreste-mexicano & \begin{tabular}{|l|} 
México, Guatemala, El \\
Salvador e Honduras
\end{tabular} & 2,18 \\
\hline Cupressus macrocarpa Hartw. Ex Gord & Tuia holandesa & Califórnia (EUA) & 0,60 \\
\hline Enterolobium contortisiliquum (Vell.) Morong. & Timbaúva & $\begin{array}{l}\text { Brasil, Bolívia, Paraguai, } \\
\text { Argentina e Uruguai }\end{array}$ & 0,16 \\
\hline Eriobotrya japonica (Thunb.) Lindl. & Nêspera & Japão e China & 0,49 \\
\hline Euphorbia cotinifolia L. & Leiteiro-vermelho & $\begin{array}{l}\text { América Central e Norte } \\
\text { da América do Sul }\end{array}$ & 0,11 \\
\hline${ }^{*}$ Eugenia uniflora L. & Pitanga & Brasil & 0,44 \\
\hline Ficus benjamina $\mathrm{L}$. & Figueira-benjamin & $\begin{array}{l}\text { Índia, China, Filipinas, } \\
\text { Tailândia, Austrália e } \\
\text { Nova Guiné }\end{array}$ & 0,55 \\
\hline Ficus lyrata Warburg & Fícus-lira & África & 0,05 \\
\hline Ficus enormis (Mart ex Miq.) Mart. & Figueira-do-mato & Brasil, Argentina, Uruguai & 0,05 \\
\hline Grevillea robusta A. Cunn. Ex R. Br. & Grevilha & Austrália & 1,64 \\
\hline Hovenia dulcis Thunb. & Uva-do-japão & Ásia & 0,16 \\
\hline "Ilex paraguariensis St. Hil. & Erva-mate & Brasil & 0,11 \\
\hline "Lafoensia pacari St. Hil. & Dedaleiro & Brasil, Paraguai & 0,44 \\
\hline Mangifera indica L. & Mangueira & Ásia, Ceilão & 0,11 \\
\hline Melia azedarach L. & $\begin{array}{|ll|}\text { Árvore de Santa } \\
\text { Bárbara }\end{array}$ & Himalia, Índia, China & 0,11 \\
\hline Morus alba L. & Amorinha & China & 0,05 \\
\hline Nerium oleander $\mathrm{L}$. & Espirradeira & Europa & 0,11 \\
\hline${ }^{*}$ Parapiptadenia rigida (Benth.) Brenan & Anjico & $\begin{array}{l}\text { Brasil, Bolívia, Paraguai, } \\
\text { Argentina e Uruguai }\end{array}$ & 0,27 \\
\hline Persea americana Mill. & Abacateiro & $\begin{array}{l}\text { América Central, Índias } \\
\text { Ocidentais, Guatemala, } \\
\text { México }\end{array}$ & 0,11 \\
\hline Pittosporum undulatum Vent. & Pau incenso & Austrália & 0,11 \\
\hline${ }^{*}$ Plinia trunciflora (Berg.) Kaus & Jaboticabeira & \begin{tabular}{|ll} 
Brasil, & Argentina, \\
Paraguai & \\
\end{tabular} & 0,22 \\
\hline Prunus serrulata Lin. $L$. & Cerejeira-do-japão & China, Japão e Coréia & 0,11 \\
\hline${ }^{*}$ Psidium catleianum Sabine & Araçá & Brasil & 0,11 \\
\hline Psidium guajava L. & Goiaba & \begin{tabular}{|lll} 
México e norte da \\
América do Sul
\end{tabular} & 0,11 \\
\hline${ }^{*}$ Rollinia rugulosa Schlecht & Araticum & Brasil & 0,22 \\
\hline Scheflera actinophylla (Endl.) Harms. & $\begin{array}{|ll|}\begin{array}{l}\text { Árvore guarda- } \\
\text { chuva }\end{array} & \\
\end{array}$ & $\begin{array}{l}\text { Austrália, Nova Guiné, } \\
\text { Java }\end{array}$ & 0,11 \\
\hline${ }^{*}$ Schinus terebinthifolius Raddi & Aroeira vermelha & \begin{tabular}{|ll} 
Brasil, & Uruguai, \\
Argentina, paraguai
\end{tabular} & 0,11 \\
\hline Senna macranthera (L.. C. Rich.) Irwin \& Barneby & Aleluia & Brasil & 0,55 \\
\hline Senna multijuga (Rich.) Irwin \& Barneby & Chuva-de-ouro & Brasil & 0,16 \\
\hline Spathodea campanulata P. Beauv. & Tulipa africana & África & 0,11 \\
\hline Tabebuia alba (Cham.) Sandw. & Ipê-amarelo & \begin{tabular}{|l} 
Argentina, \\
Brasil
\end{tabular} & 0,05 \\
\hline Tabebuia chrysotricha (Mart. Ex DC.) Standl. & Ipê-amarelo mirim & Brasil & 0,22 \\
\hline Tabebuia heptaphylla (Vell.) Tol. & Ipê-roxo & $\begin{array}{l}\text { Guianas, Peru, Bolívia, } \\
\text { Paraguai, Brasil }\end{array}$ & 0,49 \\
\hline Tibouchina granulosa Cogn. & Quaresmeira & Brasil & 0,27 \\
\hline Tibouchina mutabilis Cong. & Manacá-da-serra & Brasil & 0,27 \\
\hline Tipuana tipu Benth. Kuntze & Tipuana & $\begin{array}{|ll|}\text { Argentina, } & \text { América } \\
\text { Central, Bolívia } & \\
\end{array}$ & 2,95 \\
\hline TOTAL & & & 16,1 \\
\hline
\end{tabular}

Observações: *Espécies nativas da Floresta com araucária segundo ISERNHAGEN, SILVA e GALVÃO (2002). A origem das espécies foi obtida através das seguintes fontes: LORENZI (1992); LORENZI e SOUZA (1995); LORENZI (2002); EMBRAPA (2001); BACKES e IRGANG (2002); BACKES e IRGANG, (2004). 
Esse resultado demonstra que o bairro Centro não tem uma identidade própria do bioma local, pois das espécies que compõem a Floresta com Araucária, apenas onze estão presentes (a espécie Schinus molle na Tabela 1 e as espécies indicadas com asterisco na Tabela 2), todavia numa freqüência muito baixa. Essa falta de identidade deixa de marcar os visitantes no bairro, pois a espécie encontrada em maior proporção é comum em muitas cidades brasileiras.

\section{CONCLUSÕES}

Na composição arbórea viária do bairro Centro há predomínio de espécies exóticas, sendo que a espécie mais abundante é Ligustrum lucidum W. T. Aiton. Essa espécie atingiu uma população de 62,4\%.
Das espécies identificadas no censo, vinte e duas são nativas do Brasil, e vinte e cinco são exóticas. Dez das espécies exóticas figuram na lista das espécies invasoras do Brasil, enquanto que, do total de espécies nativas brasileiras, onze são originadas do bioma local.

\section{AGRADECIMENTOS}

À Fundação de apoio a educação, pesquisa e desenvolvimento científico e tecnológico do CEFETParaná. (FUNCEFET-PR), pelo financiamento de uma bolsa de iniciação científica.

À Prefeitura Municipal de Pato Branco/PR, pelo apoio financeiro concedido ao projeto de pesquisa.

\section{REFERÊNCIAS}

1. BACKES, P.; IRGANG, B. Árvores cultivadas no sul do Brasil: Guia de identificação e interesse paisagístico das principais espécies exóticas. Porto Alegre: Palotti, 2004. 204 p.

2. BACKES, P.; IRGANG, B. Árvores do Sul: Guia de identificação e interesse ecológico. Santa Cruz do Sul: Instituto Souza Cruz, 2002. $325 \mathrm{p}$.

3. BIONDI, D.; ALTHAUS, M. Árvores de rua de Curitiba: cultivo e manejo. Curitiba: FUPEF, 2005. 177 p.

4. CEMIG - Companhia Energética de Minas Gerais. Manual de arborização. Belo Horizonte: CEMIG, 2001. 40 p.

5. COELBA - Companhia de Eletricidade do Estado da Bahia .Diretoria de Gestão de Ativos. Departamento de Planejamento dos Investimentos. Unidade Meio Ambiente. Guia de Arborização Urbana. Salvador: Venturie Gráfica e Editora, 2002. 55 p.

6. COPEL - Companhia Paranaense de Energia. Como arborizar sua cidade: guia para os municípios. 2005. $27 \mathrm{p}$.

7. EMBRAPA - EMPRESA BRASILEIRA DE PESQUISA AGROPECUÁRIA. Centro Nacional de Pesquisa de Solos. Sistema Brasileiro de Classificação de Solos. Brasília: EMBRAPA, 1999. 412 p.

8. EMBRAPA - EMPRESA BRASILEIRA DE PESQUISA AGROPECUÁRIA. Lista das espécies - Arboretos - Construindo Ecossistemas. 2001. Disponível em <http://www.arboretos.cnpm.embrapa.br/arboreto/lista.html> Acesso em 24/07/2006.

9. FLORIANO, E.P.; GRACIOLI, C.R.; FLORIANO, A.M.; FLORIANO, R.M.M. Censo da arborização da região central da cidade de Horizontina/RS. Santa Rosa/RS: ANORGS, Prefeitura Municipal de Horizontina, Conselho Municipal do Meio Ambiente, 2004. 69 p. (Trabalho Técnico-Científico, 02).

10. GISP (EI Programa Mundial sobre Espécies Invasoras). Sudamérica invadida: el creciente peligro de las especies exóticas invasoras. Cape Town/África do Sul: GISP, 2005. 80 p.

11. IAPAR - INSTITUTO AGRONÔMICO DO PARANÁ. Cartas climáticas do Paraná. Londrina: IAPAR, 2000. CD-ROM.

12. IBGE - INSTITUTO BRASILEIRO DE GEOGRAFIA E ESTATÍSTICA. Manual técnico da vegetação brasileira. Rio de Janeiro: IBGE, 1992. $92 \mathrm{p}$

13. IBGE - INSTITUTO BRASILEIRO DE GEOGRAFIA E ESTATÍSTICA. Atlas do censo demográfico. Rio de Janeiro: IBGE, 2000. $127 \mathrm{p}$.

14. INSTITUTO HÓRUS DE DESENVOLVIMENTO E CONSERVAÇÃO AMBIENTAL/THE NATURE CONSERVANCY. Ligustrum lucidum. 2005. Disponível em <http://www.institutohorus.org.br/download/fichas/Ligustrum lucidum.htm> Acesso em 12/04/2006.

15. INSTITUTO HÓRUS DE DESENVOLVIMENTO E CONSERVAÇÃO AMBIENTAL/THE NATURE CONSERVANCY. Espécies exóticas invasoras: fichas técnicas. 2006. Disponível em <http://www.institutohorus.org.br/trabalhosa_fichas.htm > Acesso em 10/04/2006.

16. ISERNHAGEN, I; SILVA, S.M.; GALVÃO, F. Listagem de espécies arbustivo-arbóreas citadas nos trabalhos de fitossociologia florestal no Paraná, Brasil: uma contribuição aos programas de recuperação de áreas degradadas (RAD). In: A fitossociologia florestal no Paraná e os programas de recuperação de áreas degradadas: uma avaliação. Piracicaba: Instituto de Pesquisas e Estudos Florestais, 2002. v.1, p. 51-134.

17. LORENZI, H. Árvores brasileiras: manual de identificação e cultivo de plantas arbóreas nativas do Brasil. Nova Odessa: Plantarum, 1992. $352 \mathrm{p}$.

18. LORENZI, H. Árvores brasileiras: manual de identificação e cultivo de plantas arbóreas nativas do Brasil. v. 2. 2. ed. Nova Odessa: Plantarum, 2002, $368 \mathrm{p}$.

19. LORENZI, H.; SOUZA, H.M. Plantas ornamentais no Brasil: arbustivas, herbáceas e trepadeiras. Nova Odessa: Plantarum, 1995.

20. MILANO, M.S. Arborização de ruas de Curitiba/PR: uma análise qualitativa. In: ENCONTRO NACIONAL SOBRE ARBORIZAÇÃO URBANA, 1., 1985, Porto Alegre. Anais. Porto Alegre: Secretaria do Meio Ambiente, 1985. p. 83-86.

21. OJASTI, J.; JIMÉNEZ, E.G.; OTAHOLA, E.S.; ROMÁN, L.B.G. Informe sobre las especies exóticas en Venezuela. Caracas: Ministerio del Ambiente y de los Recursos Naturales, 2001.

22. RANGEL, S. A arborização urbana e o uso de espécies florestais nativas da mata atlântica. Disponível em $<\mathrm{http}: / /$ www.cpatc.embrapa.br/index.php?idpagina=artigos\&artigo=360\&showaquisicao=true $>$ Acesso em 23/02/2005.

23. RGE - Rio Grande Energia: Gestão Ambiental. Manual de arborização e poda. 2000. Disponível em <http://www.rge-rs.com.br/ gestao_ambiental/projeto_arborizacao_urbana/introducao.asp>Acesso em 20/05/2005. 
24. ROCHA, R.T. da, LELES, P.S. dos S.; OLIVEIRA NETO, S.N. de. Arborização de vias púbicas em Nova Iguaçu, RJ: o caso dos bairros Rancho Novo e Centro. Revista Árvore, Viçosa, v. 28, n. 4, p. 599-607, 2004.

25. SALATINO, A. Nós e as plantas. Revista Brasileira de Botânica, São Paulo, v. 24, n. 4 (suplemento), p. 483-490, 2001.

26. SANTOS, N.R.Z. dos; TEIXEIRA, I.F. Arborização de vias públicas: ambiente x vegetação. Porto Alegre: Palotti, 2001.135 p.

27. SARTORI NETO, J.P. Modelo de Planejamento para Convivência da Arborização com o Sistema Elétrico. In: CONGRESSO FLORESTAL ESTADUAL, 6. 1988. Anais. Nova Prata, 1988. p. 219-256.

28. SILVA, D.F. da; BORTOLETO, S. Uso de indicadores de diversidade na definição de plano de manejo de arborização viária de Águas de São Pedro - SP. Revista Árvore, Viçosa, v. 29, n. 6, p. 973-981, 2005.

29. STARR, F.; STARR, K.; LOOPE, L. Ligustrum spp.: Privet, Oleaceae. Maui: United States Geological Survey-Biological Resources Division, Haleakala Field Station, 2003. Disponível em <www.hear.org/pier/pdf/pohreports/ligustrum_spp.pdf>Acesso em 12/04/ 2006.

30. TRIGO, J.R.; SANTOS, W.F. Insect mortality in Spathodea campanulata Beauv. (Bignoniaceae) flowers. Revista Brasileira de Biologia, São Carlos, v. 60. n. 3, p. 537-538, 2000.

31. ZILLER, S. R. Os processos de degradação ambiental originados por plantas invasoras. Revista Ciência Hoje, n. $178,2001$.

Recebido em 17/10/2006 Aceito em 02/04/2007 